\title{
DESFLORESTAMENTO E MOBILIDADE EM LOTES DE PROJETO DE DESENVOLVIMENTO SUSTENTÁVEL EM ANAPU, PARÁ
}

\author{
Orlando dos Santos WATRIN ${ }^{1}$ \\ Roberto PORRO \\ Thamyres Marques da SILVA3
}

\section{Resumo}

A região da rodovia Transamazônica, no Estado do Pará, constitui uma das áreas críticas de desflorestamento na Amazônia, fruto das transformações socioeconômicas que tem atravessado. Neste trabalho é avaliada a partir de imagens TM/Landsat de 2002 e 2014, a dinâmica do desflorestamento em lotes de uso alternativo do PDS Virola-Jatobá, município de Anapu, Estado do Pará, e sua relação com a frequência de ocupação dos assentados nos mesmos. Verificou-se que em 2002 havia desflorestamento mínimo, em oposição ao incremento expressivo decorridos doze anos, ainda que em taxas de desflorestamento baixas. Uma tipologia estabelecida para o grau de desflorestamento enquadrou a maioria dos lotes em 2002, ano do início da ocupação pelos assentados, na categoria de fraco desflorestamento, enquanto que em 2014 tais registros sofrem redução, em detrimento ao crescimento de lotes com desflorestamento intenso e moderado, sendo visível a dispersão deste processo por todas as glebas. A taxa de mobilidade observada resultou em média de mais de três famílias sucedendose em cada lote, para um total de 456 ocupantes únicos. Análise estatística indicou evidência de que lotes com frequência de ocupantes não superior a duas famílias no período estudado de doze anos apresentam desflorestamento inferior aos demais.

Palavras-chave: Dinâmica da paisagem. Análise espacial. Projeto de assentamento. Frequência de ocupação. Rodovia Transamazônica.

\footnotetext{
${ }^{1}$ Eng. Agrônomo, Dr. em Geografia, Pesquisador da Embrapa Amazônia Oriental - EMBRAPA/ CPATU. Caixa Postal 48. 66095-100 - Belém, PA. E-mail: orlando.watrin@embrapa.br

2 Eng. Agrônomo, PhD. em Antropologia, Pesquisador da Embrapa Amazônia Oriental - EMBRAPA/ CPATU. Caixa Postal 48. 66095-100 - Belém, PA. E-mail: roberto.porro@embrapa.br

3 Graduanda do curso de Eng. Cartográfica e Agrimensura da UFRA. Bolsista PIBIC/ Embrapa Amazônia Oriental - EMBRAPA/ CPATU. Caixa Postal 48. 66095-100 - Belém, PA. E-mail: thamyresmsilva12@gmail.com
} 


\section{Abstract \\ Deforestation and settlers' turnover in a Sustainable Development Project in Anapu, Pará, Brazil}

The Transamazon highway region in the state of Pará, Brazil, is a critical area for Amazonian deforestation following socioeconomic transformations. Using TM / Landsat images from 2002 to 2014, we studied deforestation dynamics in lots of alternative use at the Virola-Jatobá Sustainable Development Project (PDS) in the municipality of Anapu, Pará State. In addition, we studied the relationship of deforestation with settlers' turnover within these lots. We found very limited deforestation in 2002, at the onset of the settlement. A significant increase was however observed after twelve years, although deforestation rates remained small. A typology we established for deforestation degree framed most of the 2002 lots under the "weak deforestation" category. In 2014, this category's frequency was reduced, as opposed to the increase in lots showing intense and moderate deforestation across the entire settlement area. The observed rate of turnover resulted an average of more than three families in each lot, for a total of 456 unique occupants. Statistical analysis presented strong evidence that lots where no more than two families have been settled in the studied period of twelve years are likely to show lower deforestation than others.

Key words: Landscape dynamics. Spatial analysis. Settlement project. Occupancy rate. Transamazon Highway.

\section{INTRODUÇÃO}

A conversão de floresta primária para outros usos alternativos da terra na Amazônia vem ocorrendo de forma acelerada a partir da década de 1970, em particular na região conhecida como "Arco do Desflorestamento". Tais distúrbios antrópicos constituem o processo de dinâmica de uso e cobertura da terra na região (SORRENSEN, 2009), que comumente tem início com o corte seletivo de madeira, prosseguindo por vários ciclos até a extinção das espécies comerciais. Com a perda de aproximadamente metade da estrutura da floresta primária, tem-se como prática comum o uso do fogo para preparo de área para implantação de sistemas agropecuários, principalmente pastagem, o uso da terra de maior relevância em termos de área na Amazônia (PROJETO TerraClass, 2014). Após a perda da produtividade, pelo manejo inadequado, muitas destas áreas são posteriormente abandonadas, favorecendo o processo de sucessão vegetal natural.

Uma tentativa de ordenamento da apropriação das terras na Amazônia passou a ser implementada pelo INCRA a partir de 1999, quando, em função das restrições para a criação de projetos de assentamento de reforma agrária em áreas florestadas na Amazônia ${ }^{4}$, institui a modalidade de regularização fundiária denominada Projeto de Desenvolvimento Sustentável (PDS), a partir da Portaria INCRA 477/1999, modificada pela Portaria 1040/2002. Conforme INCRA (2015) e Santos et al. (2010), o PDS constitui uma modalidade de assentamento na qual as áreas são de regime comunal de posse, emitida através de Contratos de Concessão de Direito Real de Uso (CCDRU) em nome de uma ou mais associações que congregam as famílias beneficiárias assentadas. Os PDS diferem de Reservas Extrativistas (ALLEGRETTI, 2008) ao conceder terras em áreas florestadas a agricultores sem-terra que vivem na região, mas que não necessariamente fazem parte de comunidades tradicionais extrativistas. Os beneficiários de PDS podem ter, portanto, perfis e práticas de agri-

\footnotetext{
${ }^{4}$ Lei 11.284 de 2006, que visa coibir assentamentos em florestas públicas.
} 
cultores familiares com maior integração ao mercado, cuja atividade principal não seja a extrativa, comuns às frentes de expansão agrícola em toda a Amazônia.

Em cada PDS existem Áreas de Reserva Legal (ARL) e Áreas de Uso Alternativo (AUA). A ARL em PDS somente pode ser utilizada, de forma coletiva, através de planos de manejo florestal sustentável aprovados pelos órgãos ambientais. Já a AUA é explorada em regime familiar, em lotes distribuídos pelo INCRA a cada família beneficiária. O PDS constitui, portanto, modalidade ambientalmente diferenciada de Reforma Agrária na Amazônia, sendo a subsistência baseada na agricultura familiar, extrativismo e atividades de baixo impacto ambiental, medidas estas que concorreriam para minimizar a magnitude dos desmatamentos na região.

Essa iniciativa constitui um grande desafio quando implantada particularmente em regiões mais críticas no que tange aos conflitos agrários relacionados à ocupação de áreas florestadas, como a região sob influência da rodovia Transamazônica (BR230), no Estado do Pará (BRATMAN, 2011; DE SARTRE et al., 2012; PORRO et al., 2015). Apenas na jurisdição da Superintendência do Regional do INCRA em Santarém (SR 30), no Estado do Pará, mais de 3 milhões de hectares são administrativamente designados como PDS (42 projetos em 2.260.965 ha) ou Projetos de Assentamento Extrativistas (48 PAEs em 811.477 ha), nos quais, no início de 2012, o INCRA registrava o assentamento de cerca 29.000 famílias (INCRA, 2012).

Dessa forma, os estudos que integram as dimensões ambiental e socioeconômica revestem-se de grande importância, pois podem auxiliar no entendimento dos processos de ocupação em áreas sob pressão de frentes pioneiras de ocupação. Nestes estudos, a combinação de produtos e técnicas de sensoriamento remoto e de geoprocessamento constitui ferramenta valiosa, na medida em que pode subsidiar o planejamento político e econômico para o uso adequado dos recursos naturais (WATRIN et al., 2011).

Considerando essas premissas, o objetivo deste trabalho consiste em analisar, a partir do emprego de geotecnologias, a associação existente entre o desflorestamento e a estabilidade ou mobilidade de beneficiários da reforma agrária nos lotes de uso alternativo do PDS Virola-Jatobá, no Estado do Pará. Com isto busca-se entender como se processa o desflorestamento nesta categoria de projeto de assentamento rural, considerando-se como área-piloto o exemplo selecionado.

\section{ÁREA DE ESTUDO}

A área de estudo está inserida no PDS Virola-Jatobá, localizado no município de Anapu, microrregião de Altamira, Estado do Pará (Figura 1), ocupando um total de 38.423,97 hectares. Criado pela Portaria SR01 n039/2002 (INCRA, 2015), o PDS VirolaJatobá encontra-se espacialmente dividido em dois módulos distintos, PDS Anapu III e IV, sendo neste último concentrados os 160 lotes de uso alternativo, alvo deste estudo. Tais lotes correspondem a parcelas de terra de tamanho médio de 20 hectares, destinadas ao desenvolvimento de atividades agropecuárias pelos assentados. Cabe destacar, contudo, que medidas de controle do desmatamento na Amazônia ${ }^{5}$ e no Estado do Pará6, resultaram no estabelecimento de procedimentos muito mais

\footnotetext{
${ }^{5}$ Decreto 6.321 de 21/12/2007, estabeleceu uma série de ações de forma a prevenir, monitorar e controlar o desmatamento ilegal na Amazônia, criando a Lista de Municípios Prioritários, nos quais serão priorizadas medidas de integração e aperfeiçoamento das ações de monitoramento e controle de órgãos federais, o ordenamento fundiário e territorial e o incentivo a atividades econômicas ambientalmente sustentáveis.

${ }^{6}$ Decreto estadual 54/2011 criando o Programa Municípios Verdes.
} 
rígidos para a obtenção de autorizações de supressão florestal em qualquer área de municípios considerados como embargados, ou seja, que não cumpriam com os acordos estabelecidos visando a redução do desmatamento, como é o caso de Anapu.
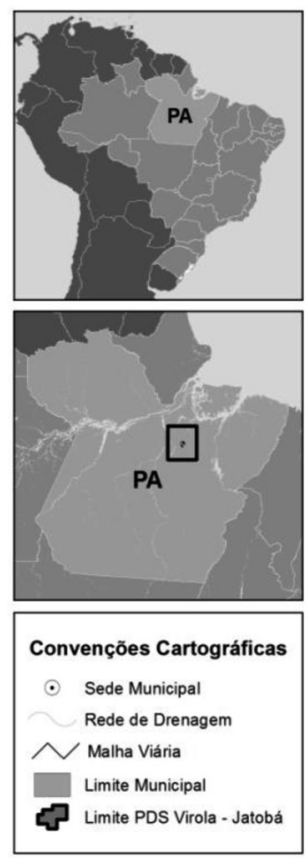

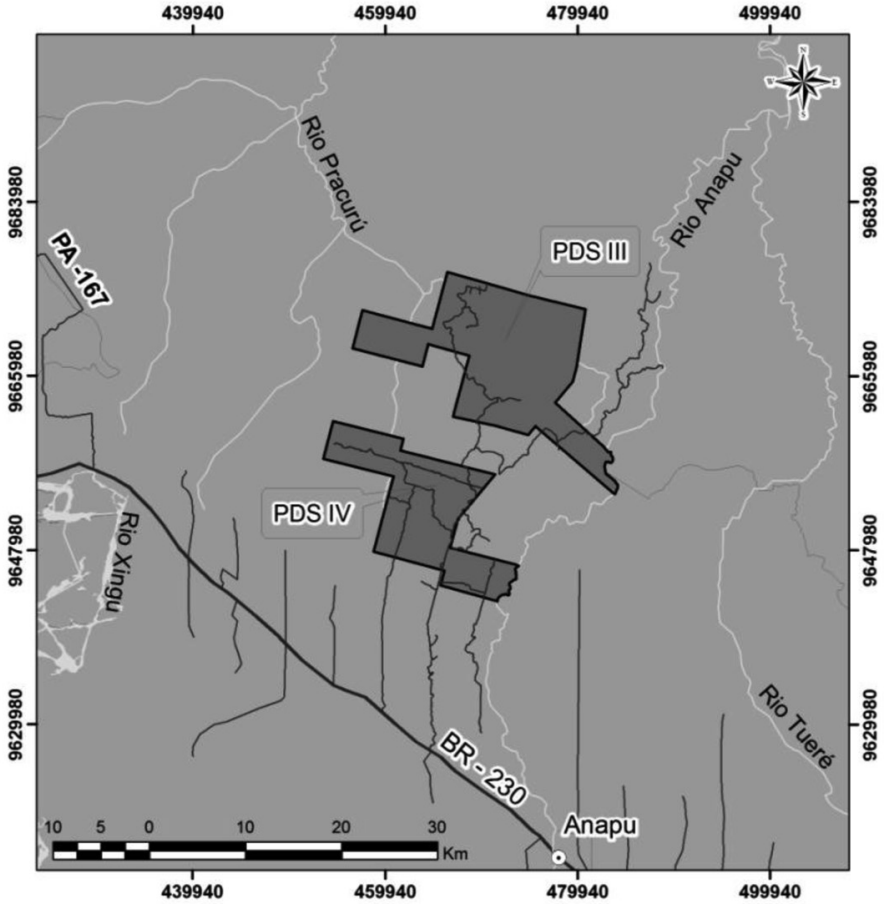

Figura 1 - Localização da área de estudo

A área destinada aos lotes de uso alternativo é drenada por igarapés tributários dos rios Anapu e Pracurú, sendo a malha viária existente subordinada à rodovia BR-230 (Transamazônica), que corre mais ao sul desta área. Segundo Rodrigues et al. (2007), os solos ocorrentes são representados pelo Latossolo Amarelo distrófico (relevo plano a suave ondulado), Argissolo Amarelo distrófico (relevo suave ondulado a forte ondulado), e Argissolo Vermelho-Amarelo distrófico (relevo ondulado a forte ondulado). Estes solos têm em comum apresentarem boas propriedades físicas (profundos, bem drenados, boa porosidade e aeração), porém com baixa fertilidade química (elevada acidez, baixa soma de bases e baixa saturação por bases trocáveis).

A cobertura da terra no PDS Virola-Jatobá ainda apresenta forte predominância de floresta, sendo esta situação observada mesmo na área de uso alternativo, onde a cobertura florestal representa cerca de $70 \%$ do total. Nas áreas desflorestadas predominam pastagens, apesar da presença de pequenas roças familiares com cultivo anuais, principalmente mandioca e milho, além de excepcionalmente serem ainda observados pequenos pomares e cultivos de cacau. Em antigas áreas de uso agropecuário abandonadas, foi favorecido o surgimento de manchas de capoeiras (sucessão secundária) com estrutura e densidades variáveis. 


\section{MATERIAL E MÉTODOS}

A partir da construção de uma base de dados espaciais na plataforma SPRING 5.3 (INPE/ DPI, 2015), foram realizados o tratamento e a análise dos dados georreferenciados de interesse, considerando-se base cartográfica do IBGE, derivada para a escala 1:50.000, considerando o sistema de projeção SIRGAS 2000. Nesta base foram ainda armazenados o limite e a grade fundiária existente para a área de estudo, sendo os mesmos delineados a partir de mapa digital do imóvel disponibilizado pelo INCRA.

Para o mapeamento dos padrões de uso e cobertura da terra foram empregadas imagens Landsat, órbita/ ponto 225/62, nas datas de 17/06/2002 (bandas TM 3, 4 e 5) e de 03/12/2014 (bandas OLI 4, 5 e 6). As imagens não foram submetidas a fase de pré-processamento, pois atualmente, conta-se com a disponibilidade de uma larga série de imagens ortoretificadas (GUTMAN et al., 2013) e com correção atmosférica (MASEK et al., 2006), que podem ser obtidas gratuitamente a partir de USGS (2015).

As imagens selecionadas foram classificadas a partir de método supervisionado por regiões, sendo para isto necessário primeiramente submetê-las ao processo de segmentação, neste caso considerando os limiares de similaridade e área de 400 e 11, respectivamente. Após a geração de arquivos de contexto, as imagens foram submetidas ao processo de extração de regiões de atributos estatísticos, de modo a permitir a classificação das mesmas. A classificação das imagens propriamente dita foi realizada pelo algoritmo Bhattacharya, tendo como base a grade de segmentação gerada anteriormente. Os produtos temáticos preliminares foram analisados em levantamento de campo e posteriormente submetidos a edições temáticas de modo a reduzir erros de omissão e comissão.

Com a obtenção das imagens temáticas dos anos de interesse, estas foram então manipuladas em ambiente ArcGIS 10.1 (ESRI, 2015), de modo a definir apenas duas classes: Floresta e Área Desflorestada, sendo esta última obtida pelo agrupamento das classes capoeira, pastagem, agricultura e queimada. Considerou-se como passível de análise apenas a área contida no limite definido pela grade fundiária do PDS estudado, sendo para isto usado esta feição como máscara de referência. Nas imagens geradas foram individualizados os lotes considerando a grade fundiária existente, possibilitando assim, com o auxílio de uma planilha Windows Excel, a realização de análises espaciais para qualificação do desflorestamento nos lotes.

A construção da planilha permitiu também a inserção de variáveis relacionadas à condição de ocupação de cada um dos 160 lotes, obtidas a partir de consulta à base de dados do INCRA, que inclui a relação de beneficiários e cadastros detalhados para cada ocupante atual. Em adição, as informações contidas na planilha derivaram de entrevistas realizadas com seis informantes-chave locais, ou seja, assentados pioneiros que residiam no PDS desde os anos iniciais de seu estabelecimento, e que são conhecedores da sequência de ocupação dos lotes nas glebas em que residem ${ }^{7}$. Tais variáveis incluíram o período de residência no lote por cada ocupante, além de dados demográficos e da condição de formalização do assentado perante o INCRA.

Dessa forma, pôde-se analisar a associação do nível de desflorestamento do lote com a variável que indica o total de ocupantes que residiu em cada lote, desde a criação do PDS. Tal variável indica o grau de estabilidade e a intensidade da mobilidade em cada um dos espaços considerados. A partir de análise nos dados de

\footnotetext{
7 O PDS Virola Jatobá consiste de um mosaico de glebas de cerca 3.000 hectares, anteriormente destinadas a empreendedores rurais que assinaram contratos de alienação de terras públicas (CATP), mas não cumpriram com suas cláusulas, sendo a terra restituída à União.
} 
desflorestamento dos 160 lotes do PDS nos anos de análise, optou-se em estabelecer categorias de desflorestamento definidas pelo método estatístico "Intervalos Idênti$\cos ^{\prime \prime}($ ESRI, 2015): Fraco $(0 \%-33,3 \%)$, Moderado $(33,4 \%-66,6 \%)$ e Intenso $(66,7 \%$ - 100\%). Para a variável frequência de ocupação nos lotes, estabeleceu-se três categorias denotando mobilidade Baixa ( 1 a 2 ocupantes no lote), Média (3 a 4 ocupantes) e Alta (cinco ocupantes ou mais), considerando o período de 2002 a 2014.

\section{RESULTADOS E DISCUSSÃO}

\section{Análise do desflorestamento nos lotes}

Do total do projeto de assentamento estudado, a área correspondente ao conjunto de lotes destinados ao uso alternativo pelos produtores contabilizou 3.332,70 ha. Deste total, no ano de criação do PDS (2002), ou seja, anterior à entrada das famílias assentadas, foram rotulados como áreas desflorestadas apenas 158,20 ha $(4,75 \%$ do total), em oposição à área observada em 2014 , onde foram registrados $1.023,67$ de áreas desflorestadas (30,72\% do total). Assim, houve um incremento de $547,07 \%$ do desflorestamento nos lotes ao longo de 12 anos, conforme pode ser observado na figura 2.

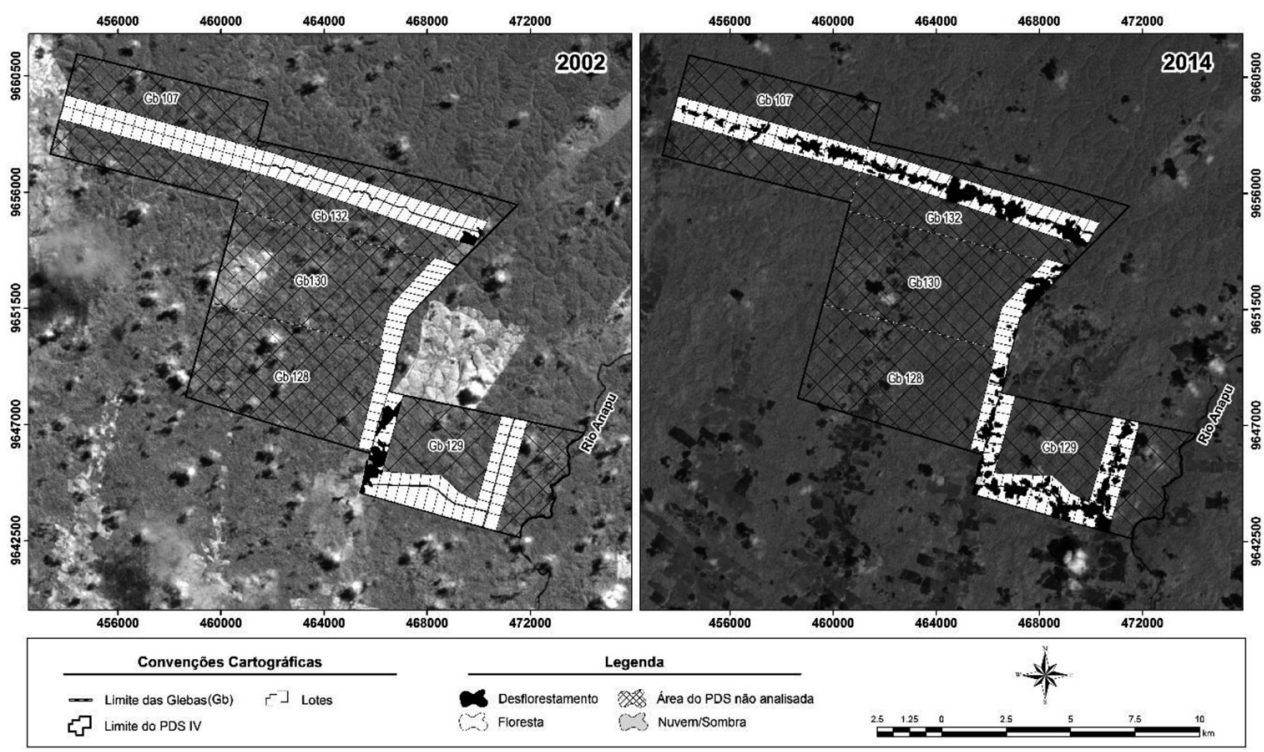

Figura 2 - Áreas desflorestadas observadas nos anos de 2002 e 2014 nos lotes de uso alternativo do PDS Virola-Jatobá, Anapu, PA

Trabalhando em projetos de assentamentos no Sudeste Paraense, Watrin et al. (2005) comentam que os processos de antropização ocorridos nas áreas estudadas tendem a apresentar trajetórias distintas, fruto das particularidades do fluxo de mi- 
gração e de estrátegias de distribuição de terras. O processo de desflorestamento é favorecido naqueles de colonização mais antiga e com o menor tamanho médio de lotes, restringindo assim a disponibilidade de recursos naturais pelo produtor.

Se houvesse uma taxa de desflorestamento linear na área de estudo no período de análise considerado (2002-2014), a mesma seria 72,12 ha/ano (2,27\%/ano), valor este considerado satisfatório para esta modalidade de regularização fundiária, pois equivaleria a 0,45 ha/ano/lote. Entretanto, conforme Watrin et al. (2005), em geral os projetos de assentamento apresentam maiores taxas de desflorestamento durante os primeiros anos, período de consolidação no uso das terras nos lotes. Com o passar do tempo, o avanço das atividades agropecuárias esgota as reservas florestais, e as taxas de desflorestamento entram em um inexorável declínio.

Quando considerada a tipologia estabelecida para o grau de desflorestamento nos lotes de uso alternativo (Figura 3 e figura 4), verificou-se um comportamento diferenciado durante os anos de análise considerados. Pelo baixo grau de desflorestamento observado no ano de 2002, os lotes foram enquadrados, em sua maioria, dentro da categoria de fraco desflorestamento, correspondendo a quase totalidade dos lotes considerados $(94,38 \%$ do total). De fato, naquele ano o desflorestamento resultou nulo em $89,47 \%$ dos lotes estudados (143 entre 160). Por outro lado, para o ano de 2014 os registros desta categoria reduziram para um pouco mais da metade $(55,62 \%$ do total) em detrimento do crescimento de lotes com intenso desflorestamento ( $5,63 \%$ do total) e, sobretudo, com moderado desflorestamento $(38,75 \%$ do total).

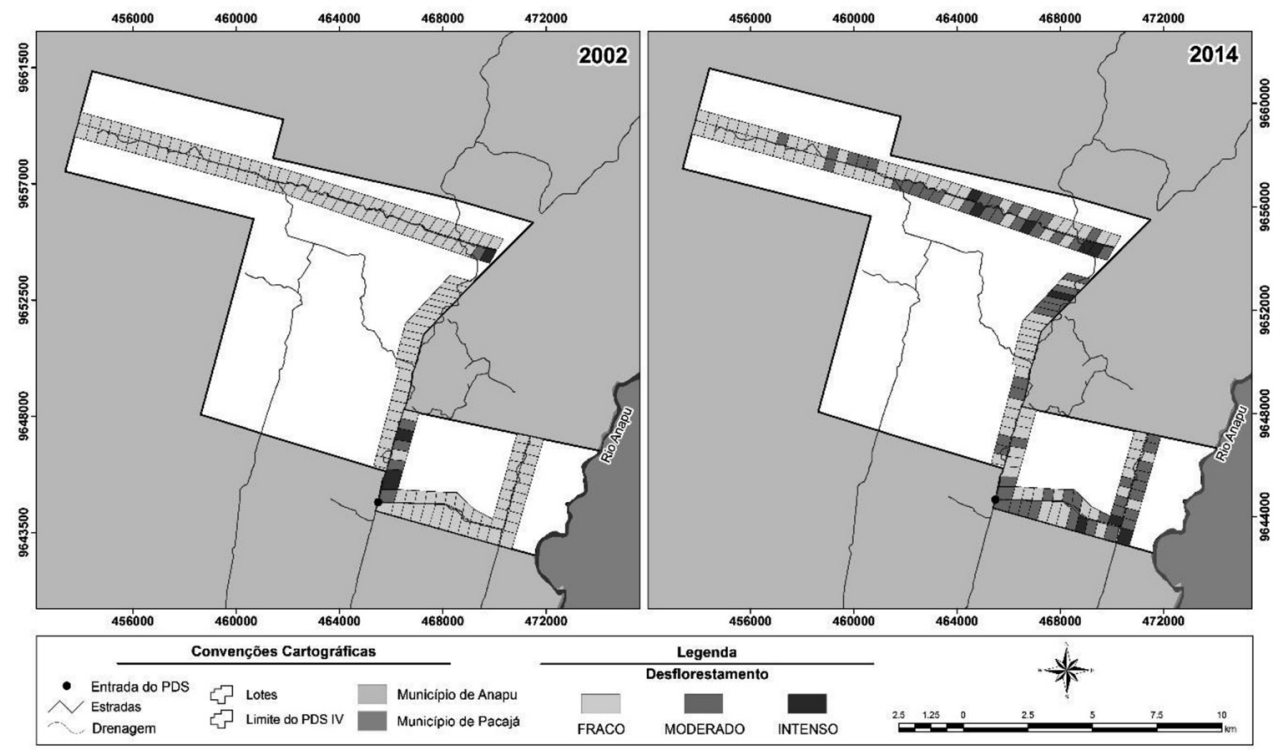

Figura 3 - Representação espacial das categorias de desflorestamento nos lotes de uso alternativo no PDS Virola-Jatobá, Anapu, PA 


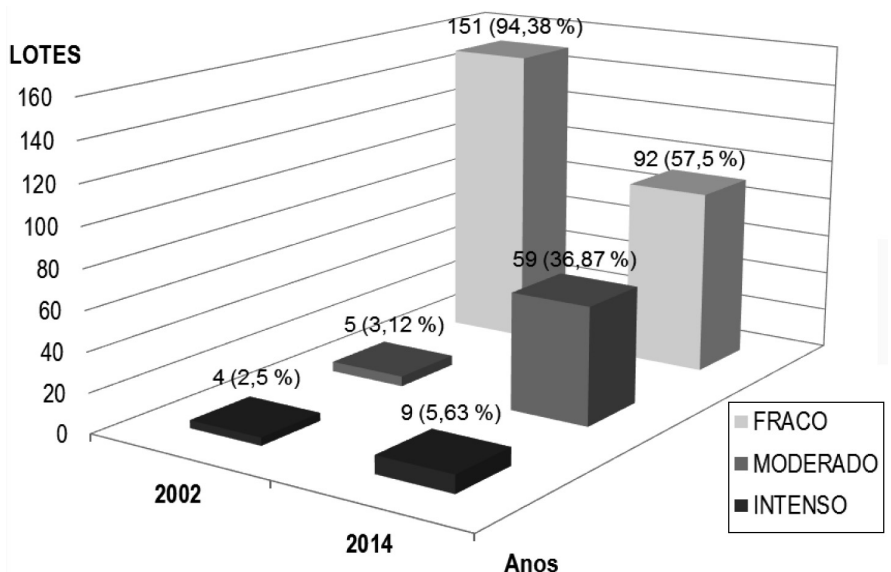

\section{Figura 4 - Quantificação das categorias de desflorestamento nos lotes de uso alternativo no PDS Virola-Jatobá, Anapu, PA}

Nesse contexto, Turner et al. (2001) destacam que o processo de mudança da cobertura do solo é geralmente acompanhado pela redução e fragmentação da vegetação nativa, eliminação de elementos ou manchas mais discretas da paisagem, redução ou eliminação de corredores, ampliação do tamanho médio das manchas de uso e, em seu extremo, simplificação e redução da diversidade de usos da paisagem. Entretanto, mesmo considerando a fragilidade dos pequenos fragmentos florestais na paisagem, Galetti et al. (2010) destacam o valor ecológico associado aos mesmos, na medida em que os fluxos entre as populações remanescentes persistem, muitas vezes sendo facilitada pela curta distância entre esses fragmentos.

Analisando a imagem temática referente a 2014, foram observadas situações em que o uso alternativo nos lotes (atividades agropecuárias) transpõe os limites estabelecidos para os mesmos, embora não seja atingido o desflorestamento total do lote, sendo este comportamento verificado em 34 lotes (21,25\% do total). Convém salientar ainda que mais da metade dos lotes com este comportamento (21 lotes ou $61,76 \%$ dos mesmos) estão concentrados nas Glebas 129 e 130, espacialmente próximas da rodovia Transamazônica.

Em outra análise, é perceptível que em 2002 os lotes com desflorestamento moderado e alto estavam concentrados na Gleba 129, próximos da atual entrada principal do PDS, enquanto as demais glebas possuíam lotes com desflorestamento geralmente nulo. Tal comportamento se explica pelo fato de que antes da criação do PDS, apenas o então detentor do CATP da atual Gleba 129 havia utilizado sua área. Por sua vez, em 2014 é visível uma dispersão do processo de desflorestamento por todas as glebas, porém com concentração da categoria intensa nas glebas 129 e 132 . Comparativamente, a gleba menos impactada corresponde a de número 107, aquela mais distante da entrada do PDS e, por conseguinte, a mais afastada da rodovia Transamazônica. Segundo os produtores, as principais limitações para ocupação dos lotes pertencentes a gleba 107 são exatamente a distância, falta de conservação da estrada de acesso, ausência de energia elétrica, além da ocorrência de diversos lotes com pouco acesso à água. 


\section{Frequência de ocupação dos lotes}

A tabela 1 apresenta o resultado do monitoramento do número de ocupantes de cada um dos 160 lotes do PDS Virola-Jatobá, distribuídos pelas quatro glebas em que estão localizadas as áreas de uso alternativo. Chama a atenção a elevada taxa de mobilidade em um período de apenas 12 anos, numa média de mais de três famílias sucedendo-se em cada lote, o que resulta em mais de 500 ocupantes. Descontados os ocupantes que saíram de lotes, mas que permaneciam em outros lotes do PDS, temos 456 ocupantes únicos. Dos 160 lotes analisados, 52 (32,5\%), 68 (42,5\%) e $37(23,12 \%)$ apresentavam taxas de mobilidade, com intensidade respectivamente baixa, intermediária e alta.

\section{Tabela 1 - Frequência de ocupantes por lote e Glebas do PDS Virola-Jatobá, Anapu, PA}

\begin{tabular}{lrrrrr}
\hline \multirow{2}{*}{ Número de ocupantes/lote } & \multicolumn{5}{c}{ Gleba } \\
\cline { 2 - 6 } & $\mathbf{1 2 9}$ & $\mathbf{1 2 0}$ & $\mathbf{1 0 7}$ & $\mathbf{1 3 2}$ & Total \\
\hline Baixa mobilidade (1-2) & 12 & 16 & 19 & 5 & 52 \\
Média mobilidade (3-4) & 17 & 11 & 13 & 27 & 68 \\
Alta mobilidade (5-9) & 15 & 4 & 5 & 13 & 37 \\
\hline Total de lotes & 44 & 32 & 38 & 46 & 160 \\
\hline Total de ocupantes na gleba & 160 & 86 & 101 & 170 & 517 \\
Ocupantes que mudaram de lote & 14 & 9 & 23 & 15 & 61 \\
Universo de ocupantes & 146 & 77 & 78 & 155 & 456 \\
Média de ocupantes por lote & 3,6 & 2,7 & 2,7 & 3,7 & 3,2 \\
\hline
\end{tabular}

Um aspecto relevante de diferenciação social entre os moradores PDS VirolaJatobá é o envolvimento das famílias no processo inicial de assentamento. Aqueles que participaram no início do processo são referidos como "pioneiros", criando laços mais politizados de confiança social. Apoiados pela Comissão Pastoral da Terra (CPT) de Anapu, estas famílias exibem maior empenho nas ações coletivas para promover laços comunitários e melhorar as condições de subsistência. De fato, agentes da CPT em Anapu estavam cientes dos impactos ambientais já verificados nos esquemas de colonização e reforma agrária na região da Transamazônica. Através da liderança da Irmã Dorothy Stang, a modalidade PDS foi proposta ao INCRA para assentar famílias sem-terra provenientes de outras localidades amazônicas. As condições peculiares de posse da terra características aos PDS, combinadas com problemas infra-estruturais (falta de estradas e outras formas de acesso) e dificuldades do meio físico (topografia acentuada e baixa fertilidade do solo), serviram como mecanismos de triagem para selecionar famílias comprometidas. Mas a confiança na CPT e movimentos sociais aliados contribuiu para que um número crescente de famílias aderisse à modalidade. Mesmo assim, muitas destas famílias foram gradualmente deixando a terra, vencidas pela falta de condições para produção. Uma orientação individual prevalece entre o grupo mais numeroso de famílias que se instalou posteriormente, denominados localmente como "novatos" (MENDES et al., 2012). Famílias sem experiência com as condições do ambiente local, sem assistência técnica e crédito adequado, e sem o vínculo e o apoio mútuo de uma comunidade, depararam-se com menor probabilidade de 
sucesso no início de seu assentamento. Tal aspecto tem acentuado uma já intensa mobilidade, a exemplo do observado em outros assentamentos amazônicos (CAMPARI, 2002; LUDEWIGS et al., 2009).

\section{Desflorestamento e frequência de ocupação dos lotes}

As análises indicaram que lotes com menor número de ocupantes apresentam em média uma menor área desflorestada (Tabela 2). Quando agregados nas três classes de frequência de ocupação nos lotes, temos que os lotes com baixa mobilidade apresentam taxa média de desflorestamento de $23,8 \%$, ao passo que os lotes com taxas de mobilidade média e alta, apresentaram desmatamento médio de respectivamente $35,7 \%$ e $34,2 \%$.

Vale salientar que nesta análise, foram excluídos oito lotes que não continham moradores, seja pelo fato de serem lotes comunitários, ou pela falta de água no lote, que uma vez constatada pelos primeiros moradores (que o abandonaram), não permitiu a reocupação do mesmo.

Tabela 2 - Relação entre desflorestamento e frequência de ocupantes nos lotes de uso alternativo no PDS Virola-Jatobá, Anapu, PA

\begin{tabular}{cccc}
\hline $\begin{array}{c}\text { Número de } \\
\text { ocupantes/ lote }\end{array}$ & $\mathbf{n}$ & $\begin{array}{c}\text { Área média do lote } \\
\text { (ha) }\end{array}$ & $\begin{array}{c}\text { Desflorestamento } \\
\text { médio (\%) }\end{array}$ \\
\hline Baixa mobilidade & 50 & 21,11 & 23,83 \\
Média mobilidade & 67 & 21,16 & 35,74 \\
Alta mobilidade & 35 & 19,63 & 34,25 \\
\hline \multicolumn{1}{c}{ Total } & 152 & 20,83 & 30,72 \\
\hline
\end{tabular}

A realização do teste de Bonferroni (Tabela 3 ) indicou significância estatística para a afirmação de que lotes com baixa mobilidade, ou seja, com frequência de ocupantes não superior a duas famílias no período de dez anos, apresentam desflorestamento inferior aos demais em pelo menos $10 \%$. A análise, contudo, não indica significância estatística para diferenças na área desflorestada nos lotes com mais de três ocupantes no período (lotes com média e alta mobilidade). 


\section{Tabela 3 - Análise estatística da relação entre desflorestamento e frequência de ocupação dos lotes de uso alternativo no PDS Virola-Jatobá, Anapu, PA}

\begin{tabular}{|c|c|c|c|c|}
\hline Mobilidade & Baixa & Média & Mobilidade & Baixa \\
\hline Média & $11.9178 * * *$ & & Outros & $11.4052 * * *$ \\
\hline Alta & $10.4240 *$ & -1.49377 & & \\
\hline$F=5,23$ & Prob $>F=0,0064$ & & $\mathrm{~F}=10,40$ & Prob $>F=0,0015$ \\
\hline
\end{tabular}

\section{CONSIDERAÇÕES FINAIS}

No ano de criação do PDS foi registrada nos lotes de uso alternativo uma parcela muito modesta de áreas desflorestadas, em oposição ao incremento bastante expressivo destas áreas decorrido doze anos. Ainda assim, considerando uma taxa de desflorestamento linear, foram obtidos valores considerados satisfatórios para esta modalidade de regularização fundiária.

Pela tipologia estabelecida para o grau de desflorestamento nos lotes de uso alternativo, observou-se em 2002, ano de instalação do PDS e início de ocupação pelas famílias assentadas, que a área que seria compreendida pela maioria dos lotes foi enquadrada na categoria de fraco desflorestamento. Já em 2012 os registros desta categoria apresentaram uma redução, em detrimento do crescimento de lotes com intenso e moderado desflorestamento.

Observou-se em 2014 situações em que o uso alternativo nos lotes transpõe os limites estabelecidos para os mesmos. Neste ano também foi visível uma dispersão do processo de desflorestamento por todas as glebas sendo, porém, a menos impactada localizada mais afastada da rodovia Transamazônica.

O monitoramento da ocupação nos lotes do PDS desde sua instalação em 2002 indica uma tendência de forte mobilidade, com média superior a três ocupantes por cada lote. Ao estudar-se a associação entre a taxa de mobilidade nos lotes e seu grau de desflorestamento, encontrou-se indícios significativos de que lotes cujos ocupantes alcançaram períodos mais longos de permanência são aqueles que apresentam menor desflorestamento.

Essa constatação reforça a importância também na dimensão ambiental de ações do INCRA e demais agências governamentais que viabilizem a consolidação do assentamento de famílias beneficiárias da reforma agrária e evitem o contínuo abandono ou transferência de lotes por parte das mesmas, o que acentua o desmatamento. Estudos mais detalhados são, contudo, necessários para a compreensão destes resultados, bem como das variáveis que possam estar influenciando os mesmos.

\section{AGRADECIMENTOS}

Este trabalho foi realizado em âmbito do projeto "Governança local e sustentabilidade do manejo florestal de base comunitária nos projetos de desenvolvimento sustentável em Anapu, Transamazônica - AutoManejo". O mesmo contou com suporte financeiro do Macroprograma 6 e do Portfolio de Recursos Florestais Nativos 
da Embrapa, assim como da Fundação Amazônia Paraense de Amparo à Pesquisa FAPESPA (ICAAF 104/2014). Agradecemos a colaboração dos residentes do PDS VirolaJatobá, sem a qual não teria sido possível a obtenção dos dados para este estudo.

\section{REFERÊNCIAS}

ALLEGRETTI, M. A construção social de políticas públicas: Chico Mendes e o movimento dos seringueiros. Desenvolvimento e Meio Ambiente, n. 18, p. 39-59, jul./dez. 2008.

BRATMAN, E.Z. Villains, victims, and conservationists? Representational frameworks and sustainable development on the Transamazon Highway. Human Ecology, v. 39, p. 441-453. 2011.

CAMPARI, J. S. Challenging the turnover hypothesis of Amazon deforestation: Evidence from colonization projects in Brazil. Austin, TX, USA. (Ph.D. Dissertation) - The University of Texas at Austin, 2002.

ESRI. ArcGIS: a complete integrated system. Disponível em <http://www.esri.com/ software/arcgis/>. Acesso em: 06 jul. 2015.

DE SARTRE, A. X.; BERDOULAY, V.; LOPES, R.S. Eco-frontier and place-making: the unexpected transformation of a sustainable settlement project in the Amazon. Geopolitics. v. 17, n. 3, p. 578-606. 2012.

GALETTI, M.; PARDINI, R.; DUARTE, J.M.; SILVA V.M.F.; ROSSI, A.; PERES, C.A. Mudanças no Código Florestal e seu impacto na ecologia e diversidade dos mamíferos no Brasil. Biota Neotropica, v. 10, n. 4, p. 47-52. 2010.

GUTMAN, G.; HUANG, C.; CHANDER, G.; NOOJIPADY, P.; MASEK, J.G. Assessment of the NASA-USGS Global Land Survey (GLS) datasets. Remote Sensing of Environment, n. 134, p. 249-265. 2013.

INSTITUTO NACIONAL DE COLONIZAÇÃO E REFORMA AGRÁRIA (INCRA). Portaria 477/041199. Disponível em: <http://www.incra.gov.br/sites/default/files/uploads/ institucional/legislacao/ portarias/portarias-de-1999/portaria_incra_p477_041199.pdf>. Acesso em: 29 maio 2015.

INSTITUTO NACIONAL DE COLONIZAÇÃO E REFORMA AGRÁRIA (INCRA). Relação de projetos de Reforma Agrária. Disponível em: <http://HYPERLINK "http:// www.incra.gov.br/index.php/reforma-agraria-2/projetos-e-programas-do-incra/ relacao-de-projetos-de-reforma-agraria/file/1115-relacao-de-projetos-de-reformaagraria"www.incra.gov.br/index.php/reforma-agraria-2/projetos-e-programas-doincra/relacao-de-projetos-de-reforma-agraria/file/1115-relacao-de-projetos-dereforma-agraria>. Acesso em: 20 mar. 2012.

INSTITUTO NACIONAL DE PESQUISAS ESPACIAIS/ DIVISÃO DE PROCESSAMENTO DE IMAGENS (INPE/ DPI). Spring: Sistema de processamento de informações georreferenciadas. Disponível em: <http://www.dpi.inpe.br/spring>. Acesso em: 11 maio 2015.

LUDEWIGS, T.; D'ANTONA, A. O.; BRONDÍZIO, E. S.; HETRICK, S. Agrarian structure and land-cover change along the lifespan of three colonization areas in the Brazilian Amazon. World Development, v. 37, n. 8, p. 1348-1359. 2009. 
MASEK, J.G.; VERMOTE, E.F.; SALEOUS, N.E.; WOLFE, R.; HALL, F.G.; HUEMMRICH, K.F.; FENG, G.; KUTLER, J.; LIM, T.K. A Landsat surface reflectance dataset for North America, 1990-2000. IEEE Geoscience and Remote Sensing Letters, v. 3, n. 1, p. 68-72. 2006.

MENDES, J.F.; PORRO, N. S. M.; SHIRAISHI-NETO, J. A "ambientalização" dos conflitos sociais no PDS Virola-Jatobá no município de Anapu, Estado do Pará. In: ENCONTRO ANUAL DA ANPOCS, 36., 21-25 out. 2012, Águas de Lindóia, SP. Anais. São Paulo, SP: ANPOCS. Disponível em: <http://portal.anpocs.org/portal/ index.php?option=com_docman\&task=doc_view\&gid=7861\&Itemid=217>. 2012.

PORRO, R.; PORRO, N.S.M.; MENEZES, M.C.; BARTHOLDSON, Ö. Collective action and forest management: institutional challenges for the environmental agrarian reform in Anapu, Brazilian Amazon. International Forestry Review, v. 17, n. 1, p. 20-37. 2015.

PROJETO TerraClass - 2012: mapeamento do uso e cobertura da terra na Amazônia Legal Brasileira. Brasília, DF: Embrapa; São José dos Campos: Inpe, 2014. [37 p.]. Disponível em: <http://www.inpe.br/noticias/arquivos/pdf/TerraClass_2012.pdf>. Acesso em: 14 set. 2015.

RODRIGUES, T.E.; SILVA, R.C.; SILVA, B.N.R.; SILVA, J.M.L. VALENTE, M.A.; DARIVA, T.A.; JESUS, A.S.; VENTURIERI, A. Caracterização, mapeamento e classificação dos solos da área de influência da BR-163 (Cuiabá- Santarém) e BR-230 (Transamazônica), no Estado do Pará. In: VENTURIERI, A. (Ed.). Zoneamento ecológico-enonômico da área de influência da BR-163 ( Cuiabá - Santarém). Belém, PA: Embrapa Amazônia Oriental. 2007. v. 2, p. 403-573.

SORRENSEN, C. Potential hazards of land policy: Conservation, rural development and fire use in the Brazilian Amazon. Land Use Policy, v. 26, n. 3, p. 782-791. Jul. 2009.

TURNER, M.G.; GARDNER, R.H.; O'NEILL, R. Landscape ecology in theory and practice: pattern and process. New York: Springer-Verlag, 2001. $401 \mathrm{p}$.

USGS. Disponível em: <http://earthexplorer.usgs.gov/>. Acesso em: 06 jul. 2015.

WATRIN, O.S.; CRUZ, C.B.M.; SHIMABUKURO, Y.E. Análise evolutiva da cobertura vegetal e do uso da terra em projetos de assentamentos na fronteira agrícola amazônica, utilizando geotecnologias. Geografia, v. 30, n. 1, p. 59-76, jan./abr. 2005. WATRIN, O.S.; OLIVEIRA, P.M.; OLIVEIRA, R.R.S. Padrões antrópicos e fisiográficos definindo unidades de paisagem na Reserva Extrativista 'Verde Para Sempre', Porto de Moz, PA. Geografia, v. 36, n. 3, p. 535-549, set./dez. 2011. 